\title{
GESTÃO DA DIVERSIDADE - UM ESTUDO SOBRE GÊNERO E RAÇA EM EMPRESAS NO BRASIL*
}

\author{
DIVERSITY MANAGEMENT - A STUDY ON GENDER AND \\ RACE IN COMPANIES IN BRAZIL
}

Stefanie Landim Reith ${ }^{1}$

Alessandra Rachid ${ }^{2}$

\begin{abstract}
Resumo
O objetivo deste texto é analisar a adoção de programas de diversidade voltados à inclusão de mulheres e negros em empresas no Brasil. As iniciativas que visam estimular a inclusão de grupos tradicionalmente discriminados no mercado de trabalho vêm crescendo em diferentes tipos de organizações, como organismos internacionais, ONG's (Organizações não Governamentais), empresa, na imprensa de negócios e associações e se reflete, ainda, na criação de leis. Para realizar a pesquisa que deu origem a este texto, foi escolhida uma amostra intencional de empresas, para verificar quantas contam com este tipo de programa e os motivos que as levaram a implantá-los. Foram escolhidas empresas que têm práticas de gestão de recursos humanos consideradas como referência, partindo da publicação "Melhores Empresas para Você Trabalhar", ligado à revista Exame. O levantamento de dados ocorreu por meio de pesquisa documental, da aplicação de um questionário em 108 empresas e da realização de entrevistas aprofundadas em quatro dessas empresas, além de entrevistas com especialistas sobre o tema. A partir dos resultados da pesquisa, foi possível observar que a quantidade das empresas pesquisadas que têm programas de diversidade é pequena, mas maior do que esperado a partir da revisão da literatura. A maior parte dos programas identificados ainda se encontrava em estágios iniciais de implantação, mas a pesquisa apresenta indícios de que a questão da diversidade veio para ficar.
\end{abstract}

Palavras-chave: Inclusão; Recursos humanos; Discriminação; Trabalho.

\begin{abstract}
The purpose of this article to analyze the adoption of diversity programs aimed at the inclusion of women and black people in companies in Brazil. Initiatives to stimulate the inclusion of groups traditionally discriminated in the labor market are growing in different types of organizations, such as international organizations, NGOs (Non-Governmental Organizations), companies, in the business press and associations, and are also reflected in the creation of laws. To carry out the research that gave rise to this
\end{abstract}

\footnotetext{
* Artigo Original: Recebido em 13/05/2020 - Aprovado em 26/10/2020.

${ }^{1}$ Mestrado em Engenharia de Produção. Analista de RH na Electrolux e Psicoterapeuta. São Carlos/SP, Brasil. e-mail: landimreith@gmail.com ORCID: https://orcid.org/0000-0002-1744-9256

${ }^{2}$ Doutorado em Engenharia Mecânica. Docente do Departamento de Engenharia de Produção, Universidade Federal de São Carlos (UFSCar), São Carlos/SP, Brasil. e-mail: arachid@ufscar.br ORCID: https://orcid.org/0000-0003-2863-055X (autor correspondente)
}

Apoio financeiro: Coordenação de Aperfeiçoamento de Pessoal de Nível Superior (CAPES) 
text, an intentional sample of companies was chosen, to verify how many count on this type of program and the reasons that led them to implement them. Companies that have human resource management practices considered as reference were chosen, based on the publication "Best Companies for You to Work", linked to Exame magazine. The data collection occurred through documentary research, the application of a questionnaire about 108 companies, and interviews in four of these companies and with experts on the topic. From the results of the research, it was possible to observe that the number of companies surveyed that have diversity programs is small, but greater than expected from the literature review. Most of the identified programs were in the initial stages of implementation, but the research shows evidence that the issue of diversity is here to stay.

Keywords: Inclusion; Human resources; Discrimination; Work.

\section{Introdução}

As iniciativas contra as diferentes formas de discriminação no mercado de trabalho vêm crescendo. Organismos internacionais, como a Organização das Nações Unidas (ONU) e a Organização Internacional do Trabalho (OIT), vêm criando programas voltados para promoção da equidade de gênero e raça desde meados dos anos 2000 (OIT BRASIL, 2013; ONU BRASIL, 2012). Observa-se, ainda, o incentivo a este tipo de iniciativa por meio de premiações e rankings elaborados por ONG's (Organizações não Governamentais), pela imprensa de negócios e associações empresariais, além de leis contra a discriminação. No Brasil, alguns dos exemplos são a inclusão do tema entre as práticas de responsabilidade social recomendadas pelo Instituto Ethos e em algumas publicações, como no caso do jornal Valor Econômico e da revista Exame (CAMPOS, 2013; EXAME, 2018; INSTITUTO ETHOS, 2010; VALOR ECONÔMICO, 2012).

Existem, ainda, leis voltadas à inclusão de certos grupos discriminados, como a lei que impõe que as empresas preencham uma porcentagem de seus cargos com beneficiários reabilitados ou pessoas com deficiência, de 1991 (BRASIL, 1991). A CLT (Consolidação das Leis Trabalhistas) prevê que não deve haver um tratamento diferenciado em função do sexo, idade, cor ou situação familiar, mas nem sempre é fácil comprovar juridicamente que uma pessoa não foi contratada por alguma dessas características (SANTOS; JESUS, 2010; ONU BRASIL, 2011). As leis não impedem a ocorrência da discriminação, mas podem levar a uma diminuição das diferenças ao longo do tempo, como Shauman e Noonan (2009) observaram que ocorreu nos EUA.
O objetivo deste artigo é analisar a adoção de programas de gestão da diversidade voltados à inclusão e permanência de mulheres e negros em empresas no Brasil. A inclusão desses dois grupos não é imposta por lei, diferente do que ocorre com as pessoas com deficiência. Desta forma, empresas que contam com este tipo de programa foram influenciadas de outra forma.

Para a realização da pesquisa, foi escolhida uma amostra intencional de empresas, para verificar quantas contam com programas de gestão da diversidade e os motivos que as levaram a implantar esses programas. Foram escolhidas empresas que têm práticas de gestão de recursos humanos consideradas como referência, partindo da publicação "Melhores Empresas para Você Trabalhar". A pesquisa foi realizada entre 2012 e 2014. As informações sobre as empresas foram colhidas por meio de pesquisa documental e da aplicação de um questionário e, em quatro delas, foram realizadas entrevistas aprofundadas. A pesquisa, contou, ainda, com uma entrevista com uma profissional que participou de uma iniciativa pioneira de diversidade no país e com a colaboração de uma participante de um comitê de diversidade ligado ao Governo Federal. Essas ferramentas de pesquisa são detalhadas adiante.

O próximo item apresenta uma breve revisão bibliográfica sobre preconceito, a consequente discriminação no mercado de trabalho, assim como sobre o surgimento de programas voltados à gestão da diversidade. Os itens seguintes apresentam a pesquisa realizada e seus resultados. 


\section{Discriminação e gestão da diversidade}

Este item apresenta uma revisão bibliográfica sobre como o preconceito atua na discriminação de mulheres e negros no mercado de trabalho e, ainda, sobre o surgimento difusão dos programas que visam a inclusão desses grupos em organizações.

O preconceito é uma atitude negativa que coloca a pessoa em uma situação injusta de desvantagem, baseando-se num processo de comparação social que se concretiza através da discriminação (GOFFMAN, 1988; JONES, 1973; SARAIVA; IRIGARAY, 2009). Quem discrimina coloca em prática uma forma de pensar que o acompanhou durante toda vida, podendo nem perceber que está discriminando. Quem é discriminado, por sua vez, se encontra em uma situação tão comum ao dia-a-dia que pode internalizar a ideia de que não é adequado para ocupar determinadas posições (KANTER, 1993; KON, 2002). Como apontado por Bourdieu (2002), o elemento simbólico de dominação é compartilhado por quem domina e por quem é dominado, fazendo com que as diferenças sejam vistas como "naturais".

Lopes (2000) ressalta que as práticas discriminatórias não se manifestam sempre de forma explícita, mas frequentemente de forma sutil e indireta. É difícil alguém dizer expressamente que não vai contratar uma pessoa por se tratar de uma mulher ou de um(a) negro(a). A dificuldade, em termos jurídicos, é comprovar a discriminação no momento de seleção para contratação ou para promoção (SANTOS; JESUS, 2010; ONU BRASIL, 2011). Essa é uma das dificuldades da aplicação de leis contra discriminação no mercado de trabalho.

A discriminação contra mulheres e negros ainda se manifesta de diversas formas. As mulheres compõem a maior parte da população economicamente ativa no Brasil, mas apresentam as maiores taxas de desemprego, além de receberem salários mais baixos, concentrarem-se mais em determinados setores econômicos e ocuparem cargos inferiores, embora sejam mais escolarizadas, como detalhado por Reith (2014).

A população negra é ainda mais discriminadai. Os negros representam mais do que a metade da população brasileira, mas são os que apresentam os maiores índices de desocupação, salários, setores de atuação e cargos ocupados. As mulheres negras enfrentam as dificuldades por causa do gênero e da raça de forma cumulativa, concentrando-se em postos de trabalho mais desprotegidos e vulneráveis (ARAÚJO; LOMBARDI, 2013; GUIMARÃES, 2002; IBGE, 2014; LOPES, 2000; SOARES, 2000).

A gestão da diversidade visa a inclusão, nas organizações, de grupos tradicionalmente discriminados no mercado de trabalho, como, por exemplo, mulheres, negros, idosos, jovens, pessoas com deficiência, homossexuais, entre outros. Seu objetivo é reconhecer e promover a diferença entre pessoas como um valor positivo, como instrumento de integração social, em benefício da produtividade das empresas e da democratização das oportunidades de acesso e tratamento no mercado de trabalho (ALEXIM, 1999; BELLAN, 2002; CAPPELLIN, 2000; GREENE; KIRTON, 2004).

Um dos países que se destaca pelo pioneirismo nessa área é os EUA. O movimento pelos direitos civis dos anos 1950 e 1960 resultaram na elaboração das primeiras leis contra discriminação racial e de ações afirmativas, uma forma do governo impor políticas de integração racial às organizações que prestavam serviços para o setor público (ANDREWS, 1985; AVRITZER; GOMES, 2013; FLEURY, 2000; MENDES, 2005; SANTOS et al., 2008).

$\mathrm{Na}$ década de 1970, o movimento feminista e a entrada de um número maior de mulheres instruídas no mercado de trabalho levaram a lutas pela igualdade entre homens e mulheres. Surgiram, então, as políticas de ações afirmativas e igualdade de oportunidades de trabalho para as mulheres (KANTER, 1993). Na Europa, essas políticas começaram a ser introduzidos no final dos anos 1960 (CAPPELLIN, 2000).

Programas de gestão da diversidade têm sido transferido para outros países, mas cada um desenvolve suas próprias políticas (AHONEM; TIENARI, 2009). Segundo Mendes (2005) e Santos et al. (2008), os programas de diversidade começaram a ser adotados no Brasil a partir da década de 1990, em empresas norte-americanas, e pela imposição legal, como a lei para pessoas com deficiência ${ }^{\text {ii }}$.

Até há poucos anos atrás, este tema era pouco difundido no Brasil. Nos últimos anos, no entanto, tem crescido sua presença em publicações da imprensa, da área de gestão, de órgãos públicos, $\mathrm{ONG}$ 'S, da área acadêmica, destacando as publicações da OIT (Organização Internacional do Trabalho) no Brasil, assim como o número de iniciativas em empresas, como detalhado por Reith, 2014. 
A implantação de um programa de diversidade exige uma série de mudanças, muitas das quais não são simples, pois envolvem o enfrentamento de questões arraigadas há tempos na sociedade e que só começaram a mudar num período relativamente recente da história (COX, 1994; KARTCHEVSKYBULPORT, 1986; GREENE; KIRTON, 2004; HIRATA; KERGOAT, 2003; LOPES, 2000; RIBEIRO, 2002; SANTOS et al., 2008).

Buscando contribuir para a compreensão dos programas de diversidade e sua difusão, foi realizada a pesquisa descrita a seguir.

\section{A pesquisa realizada}

Este item apresenta as diferentes ferramentas de pesquisa usadas para levantar informações sobre a adoção de programas de diversidade em empresas no Brasil: uma amostra intencional de empresas, cujas informações foram colhidas por meio de pesquisa documental e da aplicação de um questionário; entrevistas aprofundadas em quatro dessas empresas; entrevista com uma profissional pioneira na área de diversidade; colaboração de membro de um comitê de diversidade. A pesquisa foi desenvolvida entre 2012 e 2014 para elaboração da dissertação de mestrado de Reith (2014).

Tabela 1 - Origem do capital das 150 empresas da lista
Para a pesquisa nas empresas, foi utilizado um questionário, contendo questões abertas e fechadas sobre as empresas, seus funcionários e seus programas de diversidade. Esse questionário foi elaborado a partir de: revisão bibliográfica; da base de dados da Fundação Instituto de Administração (FIA), responsável pela pesquisa que dá origem ao ranking "Melhores empresas para você trabalhar"; de outros questionários sobre o tema desenvolvidos por universidades, organizações da área de recursos humanos e por organizações voltadas à ação afirmativa. O questionário e as referências para sua elaboração são apresentados em Reith (2014).

A pesquisa envolveu, inicialmente, 150 empresas listadas no ranking "Melhores empresas para você trabalhar", ligado à revista Exame, publicado em setembro de 2012. Optou-se por uma amostra intencional, pois se avalia que há uma maior possibilidade de adoção de práticas de diversidade entre essas empresas, incluídas nesta lista por terem políticas de gestão de recursos humanos julgadas mais avançadas.

A Tabela 1 apresenta a origem do capital destas 150 empresas. Como pode ser observado, a maior parte, 92, é de capital nacional. Em segundo lugar, estão os EUA, com 22 empresas.

\begin{tabular}{|c|c|c|}
\hline Origem do Capital & Total & Porcentagem \\
\hline Brasil & 92 & $61,3 \%$ \\
\hline EUA & 22 & $14,7 \%$ \\
\hline Alemanha & 7 & $4,7 \%$ \\
\hline Inglaterra & 5 & $3,3 \%$ \\
\hline Espanha & 5 & $3,3 \%$ \\
\hline França & 5 & $3,3 \%$ \\
\hline Suécia & 4 & $2,7 \%$ \\
\hline Itália & 4 & $2,7 \%$ \\
\hline Outros países & 6 & $4,0 \%$ \\
\hline Total & 150 & $100 \%$ \\
\hline
\end{tabular}

FONTE: Elaboração a partir de dados da EXAME (2012).

A publicação da Exame também foi usada para o levantamento de informações sobre as empresas, como ramo de atuação, número total de funcionários e quantidade de mulheres. Também foram buscadas informações nas páginas das empresas na internet, como origem do capital e formas de contato, assim como sobre ações e documentos relacionados ao tema, como guia de diversidade, o código de ética, entre outros. Desta forma, foi possível fazer 
um levantamento inicial de informações para o questionário.

Por meio das páginas das empresas na internet e de páginas de busca de telefone, obteve-se o contato de 126 empresas da lista. Realizou-se, então, o contato inicial por telefone para explicar o objetivo da pesquisa e identificar um profissional que se dispusesse a responder o questionário e a confirmar ou corrigir as informações previamente levantadas. Em alguns casos, foi necessário dizer o nome da pessoa com quem se queria falar, o que se obteve por meio das redes sociais, como o LinkedIn, ou de conhecidos com contatos nas empresas. Quando não foi possível fazer o contato por telefone, foi enviado um e-mail.

Em 21 empresas, os profissionais contatados não quiseram participar da pesquisa. Desta forma, 105 empresas da lista participaram da pesquisa. Além destas, foram pesquisadas mais três empresas: uma produtora de material escolar e uma de ensino, pela proximidade física; uma empresa do setor automobilístico que demonstrou interesse pelo tema em um evento na universidade. Apesar de não constarem da publicação, estas empresas têm suas políticas de recursos humanos como referência na região onde atuam.

A maior parte dos respondentes, 93, respondeu as questões por telefone. Para 15 deles, o questionário foi enviado por e-mail. Foram obtidas, então, informações sobre a adoção de programas de diversidade em 108 empresas. Estas são apresentadas na Tabela 2, de acordo com sua área de atuação. Para apresentação de dados sobre empresas específicas ao longo do texto, estas são identificadas por meio de nomes fictícios ligados à sua área de atuação.

Tabela 2 - Atividade econômica das empresas pesquisadas

\begin{tabular}{|c|c|}
\hline Área de atuação & Quantidade \\
\hline Auto indústria & 12 \\
\hline Serviços & 11 \\
\hline Cooperativas & 10 \\
\hline Energia & 9 \\
\hline Varejo & 7 \\
\hline Tecnologia e computação & 6 \\
\hline Construção & 6 \\
\hline Eletroeletrônico & 6 \\
\hline Farmacêutico & 5 \\
\hline Indústrias diversas & 4 \\
\hline Bens de consumo & 5 \\
\hline Química e petroquímica & 4 \\
\hline Serviços de saúde & 4 \\
\hline Siderurgia e metalurgia & 3 \\
\hline Atacado & 3 \\
\hline Bancos e serviços financeiros & 3 \\
\hline Transporte e logística & 3 \\
\hline Papel e celulose & 3 \\
\hline Telecomunicações & 2 \\
\hline Mineração & 2 \\
\hline Total & 108 \\
\hline
\end{tabular}

FONTE: Elaboração própria a partir dos dados da pesquisa. 
A maioria dos respondentes trabalha na área de gestão de recursos humanos, principalmente nos cargos de gerente, assistente e analista ou como consultores. Em 80\% das empresas, os respondentes são mulheres. Em apenas duas empresas, os respondentes tinham cargos ligados à gestão da diversidade: na Energia, onde a respondente é Coordenadora do Comitê de Gênero e Raça; e na Química, onde o respondente é Diretor de Diversidade e Inclusão.

Tabela 3 - Número de funcionários das empresas pesquisadas
Foram realizadas, ainda, entrevistas aprofundadas com funcionários de três empresas do ranking da Exame, a Energia, a Química e a Chassi e, também, com uma funcionária da Motor, empresa automotiva incluída na amostra. Estas empresas foram selecionadas para as entrevistas pelo estágio mais avançado em seus programas de diversidade ou pela riqueza das informações apresentadas no questionário, o que indica o interesse pelo tema.

A Tabela 3 apresenta dados sobre o número de funcionários das empresas pesquisadas.

\begin{tabular}{cc}
\hline $\mathrm{N}^{\circ}$ de funcionários & Empresas \\
\hline ATÉ 499 & 39 \\
500 A 999 & 10 \\
1.000 A 4.999 & 43 \\
5.000 A 9.999 & 13 \\
10.000 OU MAIS & 3 \\
\hline Total & 108 \\
\hline
\end{tabular}

FONTE: Elaboração própria a partir dos dados da pesquisa.

Também foi realizada uma entrevista com uma profissional que trabalhava na área de recursos humanos de uma confecção que realizava ações de diversidade nas décadas de 1980 e 1990, chamada aqui de Jeans. Optou-se por entrevistá-la para explorar sua experiência em uma empresa pioneira em ações de diversidade no país. A pesquisa contou, ainda, com a contribuição de uma pesquisadora que participou do comitê ad hoc do Programa Próequidade de Gênero e Raça do Governo Federal ${ }^{\mathrm{iii}}$.

Sintetizando, a pesquisa envolveu as empresas listadas na publicação da Exame, um questionário respondido sobre 108 empresas, entrevistas aprofundadas em quatro dessas e, ainda, entrevistas com especialistas.

Os próximos itens apresentam os dados sobre a presença de mulheres e negros nas empresas pesquisadas.

\section{Proporção de gênero e raça nas empresas pesquisadas}

Este item apresenta os dados sobre a proporção de homens e mulheres nas empresas pesquisadas. As informações a esse respeito nas 150 empresas listadas na publicação "Melhores Empresas para Você Trabalhar" foram sistematizadas e são apresentadas na Tabela 4. A coluna "Mais mulheres" apresenta o número de empresas que têm $60 \%$ ou mais de mulheres. Na coluna "Mais homens", estão as que têm até $39 \%$ de mulheres e, na "Proporção equilibrada", as que têm entre $40 \%$ e $59 \%$. 
Tabela 4 - Proporção de gênero nas 150 empresas da lista

\begin{tabular}{|c|c|c|c|c|}
\hline Setor Econômico & Mais mulheres & Equilíbrio & Mais Homens & Total \\
\hline Cooperativas & 10 & 2 & & 12 \\
\hline Serviços de saúde & 5 & 2 & 1 & 8 \\
\hline Bancos & 1 & 5 & & 6 \\
\hline Farmacêutico & 1 & 4 & 2 & 7 \\
\hline Telecomunicações & 1 & 1 & 3 & 5 \\
\hline Varejo & 1 & 5 & 4 & 10 \\
\hline Bens de consumo & 1 & 2 & 5 & 8 \\
\hline Atacado & & & 3 & 3 \\
\hline Indústrias diversas & & 1 & 3 & 4 \\
\hline Papel e celulose & & & 3 & 3 \\
\hline Transporte e logística & & 2 & 3 & 5 \\
\hline Eletroeletrônico & & 2 & 5 & 7 \\
\hline Mineração & & & 5 & 5 \\
\hline Serviços & & 9 & 5 & 14 \\
\hline Construção & & & 6 & 6 \\
\hline Química e petroquímica & & & 7 & 7 \\
\hline Siderurgia e metalurgia & & & 7 & 7 \\
\hline Tecnologia e computação & & 1 & 7 & 8 \\
\hline Energia & & & 11 & 11 \\
\hline Auto indústria & & & 14 & 14 \\
\hline Total & 20 & 36 & 94 & 150 \\
\hline
\end{tabular}

FONTE: Elaboração a partir de dados da EXAME (2012).

A maior proporção de mulheres é observada em 20 empresas, com forte concentração em apenas dois setores: serviços de saúde e cooperativas. As dez cooperativas em que há maior presença feminina também são da área da saúde. A proporção equilibrada ocorre em 36 empresas, com maior concentração em três setores: bancos, varejo e serviços, no qual foram classificadas as organizações de ensino. Os homens, por sua vez, são maioria em 94 empresas, sendo que isso ocorre na maior parte das empresas em seis setores: telecomunicações, bens de consumo, eletroeletrônico, indústrias diversas, transportes e logística e eletroeletrônico; também ocorre em todas as empresas de oito setores: atacado, papel e celulose; mineração, construção, química e petroquímica, siderurgia e metalurgia; energia e auto indústria.
A distribuição de gênero observada nestas 150 empresas reflete a realidade das empresas no Brasil, com a predominância masculina, sendo que a maioria das mulheres se concentra em setores tradicionalmente femininos, como observado por Brumer (1988), entre outros.

A publicação "Melhores Empresas para Você Trabalhar" não apresenta dados sobre a quantidade de negros e apenas nove empresas pesquisadas forneceram informações a respeito, como apresentado na Tabela 5, que também apresenta quais destas empresas têm programas de gestão da diversidade. 
Tabela 5 - Porcentagem de negros e programas de diversidade

\begin{tabular}{ccc}
\hline Empresa & Negros(as) & $\begin{array}{c}\text { Tem programa de } \\
\text { diversidade }\end{array}$ \\
\hline Energia & $42 \%$ & Sim \\
Logística & $32 \%$ & Não \\
Química & $16 \%$ & Sim \\
Papel & $15 \%$ & \\
Componentes Elétricos & $14 \%$ & Não \\
Motor & $13 \%$ & \\
Lápis & $10 \%$ & \\
Ensino & $6 \%$ & \\
TI & $6 \%$ & \\
\hline
\end{tabular}

FONTE: Elaboração própria a partir dos dados da pesquisa.

Como pode ser observado, a presença de negros é baixa, não chegando à metade em nenhum caso, apesar de serem mais do que a metade da população no país. No entanto, o fato dessas empresas realizarem a contagem dos funcionários de acordo com a raça, por si só, já representa um avanço, pois torna visível essa questão.

A empresa que tem maior participação de negros é a Energia, com $42 \%$. Segundo a entrevistada, isso se deve à maior concentração dessa população na Região Norte, onde a empresa se localiza. A Logística também conta com uma participação relativamente alta de negros, apesar de atuar apenas nas regiões Sul e Sudeste. Na empresa Ensino, a baixa participação de negros, $6 \%$, segundo a entrevistada, se justifica pela pouca presença dessa população na região sul do país, onde se encontra a empresa.

O entrevistado na Química afirmou que, "por questões históricas, os negros ainda têm, em média, menos qualificação e isto é utilizado como justificativa para os índices apresentados", reconhecendo a necessidade de trabalhar essa questão na empresa. Ele disse que "uma das dificuldades é conseguir uma autodeclaração de raça fiel à realidade" e, por isso, pode ser que haja mais negros do que a quantidade apresentada.
Curiosamente, a entrevistada da Chassi não divulgou os dados quantitativos sobre seus funcionários, dizendo que "esta é uma informação estratégica". Apesar disso, disse que existem "muitos negros trabalhando na produção e há um interesse em aumentar a participação dos mesmos em áreas administrativas através de uma ação do Banco para Aprendizes Negros".

$\mathrm{O}$ item a seguir apresenta dados sobre a participação desses grupos em cargos de gerência e direção.

\section{Participação em cargos de gerência e direção}

A Tabela 6 apresenta a participação de mulheres nos cargos de gerência e direção para as 12 empresas que forneceram essa informação. No conjunto, estas empresas têm $27,1 \%$ das gerências ocupadas por mulheres e $13,5 \%$ das diretorias. A Freios, a TI e a Motor não têm mulheres ocupando cargos de gerência nem de direção. Além destas, a Logística e a Energia também não possuem mulheres ocupando cargos de direção. A Material Escolar teve sua primeira mulher diretora em 2013. Apenas a Bebidas possui uma mulher como principal executiva. 
Tabela 6 - Mulheres em cargos de direção e gerência

\begin{tabular}{lccccccc}
\hline \multirow{2}{*}{ Empresa } & \multicolumn{3}{c}{ Direção } & \multicolumn{3}{c}{ Gerência } & \multicolumn{2}{c}{\begin{tabular}{c} 
ções \\
de \\
\cline { 2 - 6 }
\end{tabular}} & Total & Mulheres & $\%$ & Total & Mulheres & $\%$ & gênero \\
\hline Ensino & 32 & 11 & 34,4 & 75 & 54 & 72,0 & Não \\
Bebidas & 4 & 1 & 25,0 & 7 & 1 & 14,3 & Não \\
Varejista & 9 & 2 & 22,2 & 244 & 88 & 36,1 & Sim \\
Material escolar & 5 & 1 & 20,0 & 50 & 5 & 10,0 & Não \\
Papel & 14 & 2 & 14,3 & 78 & 14 & 17,9 & Sim \\
Química & 56 & 7 & 12,5 & 470 & 144 & 30,6 & Sim \\
Componentes elétricos & 46 & 4 & 8,7 & 241 & 46 & 19,1 & Sim \\
Energia & 5 & -- & 0 & 233 & 42 & 18,0 & Sim \\
Logística & 26 & -- & 0 & 110 & 25 & 22,7 & Não \\
Freios & 5 & -- & 0 & 12 & -- & 0 & Sim \\
Motor & 1 & -- & 0 & 12 & -- & 0 & Não \\
Tecnologia & 4 & -- & 0 & 12 & -- & 0 & Não \\
\hline Total & 207 & 28 & 13,5 & 1544 & 419 & 27,1 & \\
\hline
\end{tabular}

FONTE: Elaboração própria a partir dos dados da pesquisa.

A empresa com maior participação feminina nestes cargos é a Ensino, que têm mulheres em $34,4 \%$ das diretorias e $72 \%$ das gerências. Segundo a entrevistada, "a natureza do negócio da organização, educação, proporciona naturalmente a entrada de mulheres na organização, em diversos níveis".

Esta realidade coincide com o que foi observado em pesquisas anteriores. Os requisitos para promoção refletem os estereótipos de gênero, impedindo, sutilmente, a ascensão feminina na hierarquia das empresas (INSPER, 2013; MARTIN, 2000). Esta barreira tem sido chamada por alguns autores de "teto de vidro" (CAPPELLIN, 2008; PIRES et al., 2010; STEIL, 1997).

A Tabela 7 apresenta a participação de negros(as) em cargos de gerência e direção para as nove empresas que forneceram essa informação. Observase que a presença de negros em cargos de gerência é de $11,2 \%$. A Motor e a TI não têm negros nessa posição. Já a participação de negros(as) em cargos de direção é de 3,7\%, sendo que apenas três empresas, Componentes Elétricos, Química e Ensino, possuem funcionários nessa posição. 
Tabela 7 - Negros em cargos de gerência e direção

\begin{tabular}{ccccccccc}
\hline \multirow{2}{*}{ Empresa } & \multicolumn{3}{c}{ Direção } & \multicolumn{3}{c}{ Gerência } & \multicolumn{2}{c}{ Ações de } \\
\cline { 2 - 7 } raça
\end{tabular}

FONTE: Elaboração própria a partir dos dados da pesquisa.

Os dados das tabelas confirmam a observação de vários autores sobre as diferenças de posições no trabalho entre homens e mulheres, brancos e negros, que caracterizam uma segregação vertical, como apontam Zanoni et al. (2010). Os homens negros estão mais sujeitos a entrar no mercado de trabalho de maneira precoce e, por isso, têm mais dificuldade em obter maior nível de escolaridade, o que os coloca em inserções ocupacionais vulneráveis e cria obstáculos para ascenderem na hierarquia (DIEESE, 2007).

As mulheres vêm superando os homens em relação ao número de anos de estudo nas últimas décadas (BELTRÃO; ALVES, 2009; PIRES et al., 2010). A maior escolaridade, no entanto, não impede as mulheres de serem prejudicadas no mercado de trabalho, como apontado por vários estudos (ARAÚJO; LOMBARDI, 2013; CAPPELLIN, 2000; DIEESE, 2011; IBGE, 2012; PIRES et al., 2010; SHAUMAN; NOONAN, 2009). Entre as empresas pesquisadas, apenas a Energia forneceu dados de escolaridade, sendo que $28 \%$ dos homens possuem ensino superior completo, enquanto que para as mulheres este índice é de $42 \%$. Os pós-graduados do sexo masculino representam $7 \%$ e as mulheres, $29 \%$. Apesar disso, só 18\% das gerências são ocupadas por mulheres e nenhuma diretoria.
Os dados apresentados neste item confirmam o que é apontado pela literatura na área, destacandose a baixa participação de mulheres em cargos de gerência e direção, apesar de sua maior escolaridade. Entre os negros, a participação é menor ainda. $\mathrm{O}$ fato de as empresas terem menos dados sobre os negros indica, ainda, o menor interesse por esta questão.

O item a seguir apresenta informações sobre os programas de diversidade nas empresas pesquisadas.

\section{Gestão da diversidade nas empresas pesquisadas}

Nas 108 empresas pesquisadas, 33 (31\%) respondentes afirmaram que realizam ações de diversidade de gênero e/ou raça e 75 (69\%) responderam que não realizam. Como esperado, a maioria das empresas não realiza este tipo de ação, confirmando observações realizadas por autores como Cappellin (2000) e Mendes (2005).

A Tabela 8 apresenta informações sobre o ano em que estes programas foram criados, responsáveis e público alvo para as empresas que apresentaram esses dados. Como pode ser observado, os programas foram adotados a partir de 2000. Quatro dessas empresas contam com um comitê responsável, o que, segundo Myers (2003), é importante para administrar as atividades e realizar treinamentos regulares para conscientizar os funcionários. 
Tabela 8 - Ano de adoção, responsáveis e público alvo dos programas de diversidade

\begin{tabular}{cccc}
\hline Adoção & Empresa & Responsável & Público Alvo \\
\hline 2000 & Química & Comitê & Gênero \\
2006 & Energia & Comitê & Gênero e raça \\
2009 & Freios & Comitê & Gênero e raça \\
2010 & Compon. Elétricos & Comitê & Gênero e raça \\
2010 & Chassi & Departamento de RH & Gênero e raça \\
2013 & Papel & Área de Talent & Gênero \\
\hline
\end{tabular}

FONTE: Elaboração própria a partir dos dados da pesquisa.

A Tabela 9 apresenta a origem do capital dessas 108 empresas. A maioria é de capital nacional e, destas, apenas 23\% têm programas de diversidade. Em seguida, vêm as empresas de capital norte americano e $64 \%$ delas têm programa de diversidade, o que confirma o pioneirismo das empresas desse país. $\mathrm{O}$ número de empresas dos demais países é pequeno, não permitindo tirar conclusões a esse respeito.

Tabela 9 - Frequência de programas de diversidade e origem do capital

\begin{tabular}{lccc}
\hline \multicolumn{1}{c}{ Origem do capital } & Número de empresas & Têm programa de diversidade & $\%$ \\
\hline Brasil & 71 & 16 & $23 \%$ \\
EUA & 13 & 8 & $64 \%$ \\
Alemanha & 6 & 2 & $33 \%$ \\
Espanha & 3 & 2 & $67 \%$ \\
França & 3 & 1 & $33 \%$ \\
Suécia & 3 & 2 & $67 \%$ \\
Itália & 3 & 1 & $33 \%$ \\
Inglaterra & 2 & 1 & $50 \%$ \\
Suíça & 1 & 0 & 0 \\
Dinamarca & 1 & 0 & 0 \\
Japão & 1 & 0 & 0 \\
Bélgica & 1 & 0 & 0 \\
\hline Total & 108 & 33 & $31 \%$ \\
\hline
\end{tabular}

FONTE: Elaboração própria a partir dos dados da pesquisa.

O pioneirismo de empresas norte americanas foi confirmado, também, na entrevista com a profissional que trabalhou na Jeans, multinacional situada na cidade de São Paulo, que desenvolvia programas de diversidade desde a década de 1980, antes mesmo do que é apontado por diferentes autores. Essas políticas eram impostas pela Matriz, localizada em São Francisco, Califórniaiv .

A influência da matriz também pode ser observada no caso de outras empresas multinacionais. De acordo com a entrevistada na Chassi, de origem sueca, "as diretrizes chegam até as empresas no
Brasil". Na Componentes Elétricos, francesa, os programas de diversidade também são determinados pela matriz, que impõe ações globais que devem ser desenvolvidas por grupos locais, como ocorre nas plantas da empresa no Brasil. A influência da matriz também ficou bem clara no caso da Freios.

Foi identificado um caso de empresa multinacional cuja iniciativa de implantar programas de diversidade se iniciou no Brasil. Segundo o entrevistado na Química, em 2000 surgiram as primeiras ações pontuais. Em 2003, foi criado um comitê de diversidade e, em 2005, foi criado um 
guia de diversidade para auxiliar os gestores com essas questões. Em 2008, foi realizado o censo das unidades da América Latina, o que influenciou na realização do primeiro censo de toda a empresa no mundo no ano seguinte. $\mathrm{O}$ entrevistado afirma que a matriz "dá bastante liberdade para desenvolver ações de diversidade" e incentiva a troca de experiências com unidades em outros países.

$\mathrm{Na}$ Energia, uma influência importante foi o Programa Pró-equidade de Gênero e Raça, criado em 2005 pelo Governo Federal (SPM, 2016). A empresa já contava com algumas iniciativas antes, como o abrigo para mulheres vítimas de violência e a participação em conselhos municipais de direito da mulher. Em 2006, ela foi uma das primeiras empresas a aderir ao Programa Pró-equidade. Segundo a entrevistada, para participar desse programa, as empresas devem seguir um modelo estruturado de gestão das ações de diversidade, o que exige que elas se tornem mais organizadas. A pesquisadora pertencente ao comitê ad hoc confirmou que o programa exige muito compromisso e que as empresas devem fornecer muitas informações. "Não é cosmética".

A Tabela 10 apresenta a presença de programas de diversidade de acordo com o porte das 108 empresas pesquisadas. Com exceção das empresas com mais de 10 mil funcionários, que são apenas três, observa-se que a porcentagem de empresas que têm programas de diversidade cresce juntamente com seu tamanho. As empresas maiores normalmente contam com mais recursos e têm uma estrutura organizacional que facilitam seu envolvimento neste tipo de iniciativa.

Tabela 10 - Número de funcionários e programas de diversidade

\begin{tabular}{lccc}
\hline Número de Funcionários & Número de Empresas & Têm programas de diversidade & $\%$ \\
\hline até 499 & 39 & 6 & $15 \%$ \\
500 a 999 & 10 & 2 & $20 \%$ \\
1.000 a 4.999 & 43 & 16 & $37 \%$ \\
5.000 a 9.999 & 13 & 8 & $62 \%$ \\
10.000 ou mais & 3 & 1 & $33 \%$ \\
\hline Total & 108 & 33 & $31 \%$ \\
\hline
\end{tabular}

FONTE: Elaboração própria a partir dos dados da pesquisa e de EXAME (2012).

A Tabela 11 apresenta alguns exemplos de ações de diversidade apresentados pelos respondentes. A maioria desenvolve eventos que estimulam a diversidade, mas apenas programas mais antigos, como os da Química e da Energia, realizam ações abrangentes como adaptação do espaço e dos materiais de trabalho, contratação de mulheres para cargos tradicionalmente masculinos, desenvolvimento de liderança entre as mulheres e elaboração de um guia de diversidade. 
Tabela 11 - Ações de diversidade mencionadas pelos respondentes

\begin{tabular}{|c|c|c|}
\hline Ações & Gênero & Raça \\
\hline Estímulo a denúncias & 6 & 6 \\
\hline Controle salarial & 6 & 5 \\
\hline Palestras e eventos para todos os funcionários & 5 & 4 \\
\hline Programa educacional & 5 & \\
\hline Palestras e eventos para líderes & 4 & 3 \\
\hline Auxílio creche & 4 & \\
\hline Kit maternidade & 2 & \\
\hline Extensão da licença maternidade & 2 & \\
\hline Desenvolvimento de líderes mulheres & 2 & \\
\hline Guia de diversidade & 1 & 1 \\
\hline Tema na prova de contratação & 1 & 1 \\
\hline Estímulo à contratação de estagiários & 1 & 1 \\
\hline Estímulo à contratação de aprendizes & 1 & 2 \\
\hline Adaptação espacial e de materiais de trabalho & 1 & \\
\hline Meio período em casa após a licença maternidade & 1 & \\
\hline Participação de mulheres na comissão de recrutamento e seleção & 1 & \\
\hline Orientação de orçamento familiar & 1 & \\
\hline Auxílio para filhos excepcionais & 1 & \\
\hline Lactário & 1 & \\
\hline Busca por fornecedores que estimulam a diversidade & & 1 \\
\hline Parceria com universidades para a contratação de negros(as) & & 1 \\
\hline
\end{tabular}

FONTE: Elaboração própria a partir dos dados da pesquisa.

Quatro empresas forneceram mais detalhes sobre como realizam o controle salarial. Nas empresas Freios, Chassi e Varejista, o controle é feito por meio de uma tabela salarial organizada por $\operatorname{cargos}^{\mathrm{v}}$. $\mathrm{Na}$ Papel, "há uma análise de remuneração semestral para verificar a diferença entre homens e mulheres, por nível, área, localização, entre outras variáveis".

A Energia tem iniciativas voltadas à conscientização dos trabalhadores em relação a sua raça. No dia da Consciência Negra, são realizadas palestras sobre o movimento negro, apresentações de capoeira, grupos de dança afro, entre outros, dentro e fora da empresa. Segundo a entrevistada, essas iniciativas conseguiram sensibilizar e mobilizar as pessoas e $96,7 \%$ declarou sua raça na ficha de perfil. A empresa faz um trabalho com as lideranças, para prepara-los a lidar com a diversidade e desconstruir o discurso de que "o quadro demora para mudar e que as coisas são assim mesmo”.
Na Chassi, o programa de desenvolvimento de líderes tem que apresentar uma proporção equilibrada de gênero, a comissão de recrutamento e seleção para cargos gerencias tem que ter a participação de pelo menos uma mulher e entre os candidatos finais, uma deve ser mulher. Segundo a entrevistada, "esses incentivos têm o objetivo de amenizar a tendência dos homens a sempre procurarem outros homens para o trabalho".

Apesar de responder que não realiza ações de gênero e raça, a respondente apontou algumas iniciativas na Material Escolar, como a opção por negros(as) em caso de empate no processo de seleção, o incentivo a denúncias e o controle salarial por cargos.

Como pode ser observado, a maior parte das ações é voltada para a questão de gênero, como já havia sido observado em estudos anteriores (INSTITUTO ETHOS, 2010; MENDES, 2005). Cabe ressaltar que algumas das ações apontadas, quando são voltadas 
apenas para as mulheres, fortalecem a divisão sexual do trabalho, pois reforçam a atribuição de responsabilidade por questões familiares a elas.

Foram mencionadas, ainda, algumas ações voltadas para outros grupos tradicionalmente discriminados, sem considerar a inclusão de pessoas com deficiência, exigida por lei. A Química já foi líder do fórum empresarial do direito LGBT (lésbicas, gays, bissexuais e transgêneros). A empresa estendeu o plano de saúde para o parceiro do mesmo sexo, assim como a Energia faz desde 2000. A Motor está se adaptando para isso, mas a entrevistada cita a dificuldade de cadastrar o parceiro homossexual no sistema, pois "este ainda não identifica um parceiro do mesmo sexo".

A Química e a Energia foram as duas únicas empresas que mencionaram ações voltadas a indígenas, o que também não é muito explorado na literatura sobre gestão da diversidade em empresas. A Energia realiza um programa com os índios Parakanã, que foram afetados diretamente pela construção da planta, próxima à aldeia. Também neste caso, a empresa tem poucas autodeclarações de indígenas.

A Energia vai implantar, ainda, banheiro transgênero nos prédios que são mais visitados e está trabalhando a questão do documento de identidade social, que permite a pessoa ter um documento de identificação interno com o nome que quer e não o da certidão de nascimento. A Química e a Freios mencionaram, ainda, a existência de programas para pessoas com idade avançada e para manifestações religiosas.

Os entrevistados apontaram várias dificuldades ligadas ao desenvolvimento de programas de diversidade. Apesar dessas dificuldades, alguns respondentes conseguem observar mudanças nos últimos anos.

Poucas empresas, no entanto, apresentam dados sobre a proporção de mulheres e negros para anos anteriores, apenas a Energia, a Papel, que têm programa de diversidade, e a Logística, que não tem, mas mantêm registro dessas informações. $\mathrm{Na}$ Energia, houve um aumento da participação de negros na empresa como um todo entre 2008 e 2013. Nos cargos de gerência, houve um aumento de $24 \%$ na presença de mulheres e de $33 \%$ na de negros. $\mathrm{Na}$ Papel, houve um aumento de $54 \%$ na participação de negros entre os funcionários horistas entre 2010 e 2013. A participação de mulheres na empresa aumentou $12 \%$, sendo que duas delas passaram a ocupar cargos de direção. Na Logística, houve um aumento muito significativo de mulheres e negros, inclusive em cargos de gerência, mas isso ocorreu em função de aquisições de outras empresas nos anos anteriores à pesquisa. Não há negros na direção de nenhuma dessas três empresas.

Poucas empresas têm programas de diversidade e sua adoção vem ocorrendo a partir do ano de 2000. Foi apresentada uma grande variedade de ações relacionadas à diversidade, mas poucos dados sobre os resultados alcançados. Entre as empresas que apresentaram esses dados, foi possível observar uma evolução.

\section{Argumentos sobre diversidade}

As empresas investigadas reconhecem a discrepância da participação por gênero e raça. $\mathrm{O}$ que as diferencia são os argumentos a respeito dessas diferenças e como reagem a elas. Para algumas empresas que não realizam ações de diversidade, como é o caso da Motor, TI e Bebidas, as diferenças de gênero são consideradas "naturais" do setor de atuação pelos profissionais que foram entrevistados.

Em algumas empresas, os respondentes ainda veem as ações voltadas à diversidade como injustas. A respondente da TI, por exemplo, diz que "não vemos sentido em programas diferenciados para mulheres, negros, etc.” A respondente da Papel diz que "não temos nenhum tipo de discriminação. A empresa contrata profissionais pela competência e não por outras características". A respondente da Logística completa: "Afinal, o que importa para a empresa é a competência do colaborador”.

Isso se observa mesmo em empresas com programas de diversidade, como no caso da Chassi, cujas ações nesta área, segundo a entrevistada, são "indiretas e realizadas com cuidado para não diferenciar as pessoas [...] Não vamos contratar uma mulher ou um negro só para diversificar. Incentivamos a chegar até o fim, mas escolhemos apenas os melhores". Ao mesmo tempo, quando questionada sobre as dificuldades relacionadas a essas ações, ela aponta: "nossa cultura não está preparada para lidar com a diversidade [...] somos cobrados por resultados e pessoas que pensam de forma diferente podem atrapalhar esse processo". 
Em algumas empresas, a proporção equilibrada ou a maioria feminina é usada como justificativa para não desenvolverem ações de diversidade. Na Ensino, por exemplo, a entrevistada disse que "há um número significativo de mulheres na organização. Não precisamos deste tipo de ações". Sua avaliação reflete uma ideia relativamente comum, de que a as ações de diversidade restringem-se apenas ao recrutamento e seleção. A diversidade, no entanto, deve envolver várias outras atividades, como apontado por CAPPELLIN (2000), para quem a igualdade de tratamento deve envolver o acesso ao trabalho, a formação, a retenção, a promoção profissional, as condições trabalho e a remuneração, assim como o reconhecimento de que não há neutralidade nesses processos.

Em algumas empresas, como na TI, Varejista, Logística e Ensino, os entrevistados preocupam-se em deixar claro que a empresa não possui preconceito e segue um código de ética. Entretanto, nota-se a falta de flexibilidade para lidar com novas demandas.

Os entrevistados da Jeans, Química e Chassi ressaltaram que a cultura brasileira não está preparada para lidar com a diversidade, pois é racista e machista. As ações de diversidade mexem com o status atual do homem branco e isto causa resistência de alguns líderes. Segundo a entrevistada na Motor, o tema é novidade nas empresas e, para evitar transtornos, "é mais fácil continuar contratando o homem branco heterossexual".

Alguns respondentes apresentaram o argumento das soft skills, ou seja, características consideradas "naturais" das mulheres para aumentar sua presença. Esse tipo de argumento é criticado por diferentes autores, pois reforça a divisão sexual do trabalho. Estas não são características biológicas, naturalmente inerentes às mulheres, e sim adquiridas ao longo de seu processo de socialização (KERGOAT, 1987; LEITE; POSTHUMA, 1996). Segundo Kon (2002), esta feminização se apoia na situação marginal da mulher no mercado de trabalho e nas suposições de docilidade e domesticidade como facilitadores das relações de trabalho.

Percebe-se que os argumentos se modificam nas empresas mais engajadas com questões de diversidade, como no caso da Energia, Química, Componentes Elétricos e Freios. Se o setor de atuação é predominantemente masculino e o perfil da região geográfica é predominante branco, essas não são entendidas como situações "naturais". Ao invés disso, são vistas como dificuldades que devem ser enfrentadas para o estabelecimento do equilíbrio de gênero e raça no quadro de funcionários. Já que as pessoas não são iguais, suas necessidades também não são e isto não representa injustiça e sim respeito.

\section{Conclusões}

Foram pesquisadas empresas de uma amostra intencional elaborada a partir da publicação "Melhores para Você Trabalhar", que classifica empresas com práticas de gestão de recursos humanos mais avançadas, acreditando-se que estas teriam maior chance de adotarem práticas de diversidade. Entre as empresas contatadas, 105 forneceram informações sobre os programas de diversidade. Além dessas, foram incluídas mais três empresas, totalizando 108 empresas pesquisadas. Em quatro delas, também foram realizadas entrevistas.

Diversas pesquisas apontam que a discriminação ainda representa uma barreira para a inserção de mulheres e negros no mercado de trabalho. Nas 150 empresas da publicação, a maior presença feminina só é observada no setor de saúde, seja em cooperativas ou empresas privadas, e em proporção equilibrada em bancos e serviços. Os homens são maioria na maior parte dos setores.

A literatura ainda aponta que os homens brancos ocupam cargos de comando, dominam determinados setores, recebem salários mais altos e, muitas vezes, essa situação estabelece um padrão de contratação que a realimenta. Entre as empresas que forneceram esta informação, a participação feminina em cargos de gerência é de $27 \%$ e, em cargos de direção, 14\%, sendo que são a metade da população. A participação de negros(as) é ainda menor: 11\% nos cargos de gerência e 4\% nos cargos de direção, sendo que são mais da metade da população.

Os negros(as) são tema de uma quantidade menor de estudos se comparados às mulheres e existem menos programas de incentivo à diversidade de raça, como foi observado na revisão bibliográfica e nas empresas pesquisadas.

$\mathrm{Na}$ época da pesquisa, a quantidade de estudos sobre a presença de negros no mercado de trabalho era menor do que sobre a presença de mulheres e existiam menos programas de incentivo à diversidade de raça em empresas no país, como foi apontado na revisão bibliográfica. Isso também foi observado na 
revisão bibliográfica e nas 108 empresas pesquisadas. Apenas seis das empresas pesquisadas forneceram dados sobre a cor dos trabalhadores.

Entre as 108 empresas pesquisadas, 33 realizam ações de diversidade e 75, não. Esta quantidade é pequena, mas maior do que se esperava, uma vez que a literatura aponta que estas práticas são pouco comuns no Brasil. Se nestas empresas, que têm práticas avançadas de recursos humanos, a maior parte evidencia pouco conhecimento em relação a ações de diversidade, é pouco provável que isto esteja mais avançado em outras empresas no país.

Pode se observar que a adoção de programas de diversidade tende a crescer juntamente com o porte das 108 empresas pesquisadas. Entre as empresas com menos de 500 funcionários, apenas 15\% tinham adotado esses programas. Esta porcentagem cresce até $56 \%$ entre as empresas com 5 mil funcionários ou mais.

Identificou-se que uma influência para adoção desses programas provém da sede de empresas multinacionais, destacadamente nos casos das norteamericanas. Outra influência que pode ser observada na pesquisa vem de programas do Governo Federal, que têm levado à difusão dessas iniciativas, principalmente em empresas estatais, como no caso da Energia, que foi muito influenciada pelo Programa Pró-equidade de Gênero e Raça.

Além destas, durante a pesquisa foram identificadas várias iniciativas voltadas à promoção da diversidade, como as da ONU e da OIT, assim como premiações e rankings elaborados por ONG's (Organizações não Governamentais), pela imprensa de negócios e associações empresariais. Portanto, parece que está ocorrendo uma conjunção de influências relacionadas a essas ações.

Confirmando o que diz a literatura, observa-se que a maior parte dessas iniciativas é recente. Entre as empresas pesquisadas, o programa mais antigo é o da Química, implantado em 2000.

A partir da observação das diferentes empresas, foi possível identificar quatro estágios de implantação dos programas de diversidade:

1. O estágio em que as empresas não desenvolvem e nem demonstram interesse de desenvolver ações de diversidade;
2. O estágio inicial, no qual as empresas demonstram a intenção de implantar e estão buscando mais informações sobre o tema;

3. O estágio intermediário, em empresas que já implantaram algumas ações mais comumente observadas, como a promoção de eventos e palestras, controle salarial e estímulo a denúncias. Nestas, muitas vezes ainda se observam argumentos contraditórios ou mesmo que reafirmam o processo de discriminação.

4. O estágio avançado, de empresas que possuem um conjunto de ações mais integradas, como elaboração de um guia de diversidade, existência de um comitê de diversidade e de cargos dedicados a essa questão. Nestas empresas, os argumentos são mais elaborados, mas também puderam ser observadas diferenças entre elas.

Apenas três empresas apresentaram dados sobre a evolução da proporção de mulheres e negros. Ressalta-se que o acompanhamento desses dados é importante para avaliar os resultados dos programas de diversidade e para realizar aperfeiçoamentos.

Curiosamente, o caso em que pode ser verificado o maior crescimento no número de mulheres e negros foi de uma empresa que não tem programa de diversidade, a Logística, em função das aquisições mencionadas pela respondente. De qualquer forma, seria interessante realizar estudos longitudinais em empresas com programas mais antigos, como no caso da Jeans, para compreender seu processo de aprendizado e observar seu efeito ao longo do tempo.

Seria interessante, ainda, avançar em relação aos resultados observados com pesquisas comparativas entre empresas de capital nacional e de capital originário de outros países, entre empresas públicas e privadas, o que permitiria compreender as vantagens e as limitações de cada um desses tipos de organização e as adaptações das práticas utilizadas. Cabe, também, observar o destino dos programas do Governo Federal nesta área em novos mandatos do executivo.

A pesquisa foi realizada em uma amostra intencional de empresas, o que não permitiria a generalização de seus resultados. Estes, no entanto, reforçam observações de pesquisas de outros autores de que programas de gestão da diversidade bem estruturados são raros em empresas no Brasil. 
A maior parte dos programas que existem são iniciativas recentes que estão se estruturando. A época de realização da pesquisa parece representar um momento de inflexão em relação ao tema gestão da diversidade, em que este começa a fazer parte da agenda das organizações.

\section{Referências}

AHONEM, Pasi; TIENARI, Janne. United in Diversity? Disciplinary Normalization in an EU Project. Organization, v. 16, n. 5, p. 655-679, 2009.

ALEXIM, João C. As Questões de Diversidade e o Papel da Educação Profissional. Brasília: Projeto OIT/Mtb/CERT/DIV, 1999.

ANDREWS, George R. O negro no Brasil e nos Estados Unidos. Lua Nova, v. 2, n. 1, p. 52-56, 1985.

ARAÚJO, Angela M. C.; LOMBARDI, Maria R. Trabalho Informal, Gênero e Raça no Brasil do Início do Século XXI. Cadernos de Pesquisa, v. 43, n. 149, p. 452-477, 2013.

AVRITZER, Leonardo; GOMES, Lilian C. B. Política de reconhecimento, raça e democracia no Brasil. Dados, v. 56, n. 1, p. 39-68, 2013.

BELLAN, Ana C. Diversidade e Discriminação. In: DIAS, Jussara; FREIRE, Lucienne (org.). Diversidade: Avanço Conceitual para a Educação Profissional e o Trabalho. Brasília: Oficina Internacional Del Trabajo, 2002. p. 15-24.

BELTRÃO, Kaizô I.; ALVES, José E. D. A Reversão do Hiato de Gênero na Educação Brasileira no Séc. XX. Cadernos de Pesquisa, v. 39, n. 136, p. 125-156, 2009.

BOURDIEU, Pierre. A Dominação Masculina. Rio de Janeiro: Bertrand Brasil, 2002.

BRASIL. Lei no 8.213. Brasília, 1991. Disponível em: <www.planalto.gov.br/ccivil_03/leis/18213cons. htm>

BRASIL. Ministério da Ciência, Tecnologia e Inovações. INCT consolida dados sobre política de inclusão no ensino e pesquisa. 2014. Disponível em: <https://antigo.mctic.gov.br/mctic/opencms/ salaImprensa/noticias/arquivos/migracao/2014/06/ INCT_consolida_dados_sobre_politica_de inclusao_no_ensino_e_na_pesquisa.html? searchRef $=$ inct $\&$ tipoBusca $=$ expressaoExata $>$

BRASIL. Portaria No 43, Brasília, 2011. Disponível em <http://www.normaslegais.com.br/legislacao/ portariasmp43_2011.htm>
BRUMER, Anita. O Sexo da Ocupação Considerações Teóricas Sobre a inserção da mao de obra Feminina na Força de Trabalho. Revista Brasileira de Ciências Sociais, n. 8, v. 3, p. 20-38, 1988.

CAMPOS, Stela. Liderança Feminina. Valor Econômico, 08 mar. 2013.

CAPPELLIN, Paola. Ações afirmativas, gênero e mercado de trabalho: a responsabilidade social das empresas na União Européia. In: ROCHA, Maria I. B. da (org.) Trabalho e Gênero - Mudanças, permanências e desafios. São Paulo: Editora 34, 2000. p. 265-294.

CAPPELLIN, Paola. As desigualdades impertinentes: telhado, paredes ou céu de chumbo? Gênero, v. 9, p.89-126, 2008.

CARDOSO, Clarice. Inclusão por cotas - Instituições federais devem aumentar em seis vezes o número de ingressantes negros no País. Carta Capital, n. 70, out. 2013.

COX, Taylor. Cultural Diversity in Organizations: Theory, Research and Practice. São Francisco: Berrett-Koehler Publishers, 1994.

DEPARTAMENTO INTERSINDICAL DE ESTATÍSTICA E ESTUDOS SOCIOECONÔMICOS - DIEESE. Escolaridade e Trabalho: desafios para a população negra nos mercados de trabalho metropolitanos. São Paulo, 2007.

DEPARTAMENTO INTERSINDICAL DE ESTATÍSTICA E ESTUDOS SOCIOECONÔMICOS - DIEESE. Anuário das Mulheres Brasileiras. São Paulo, 2011.

EXAME. As melhores empresas para você trabalhar. Guia 2012 Você S/A. Editora Abril, set. 2012.

EXAME. Guia Exame Diversidade mapeia iniciativas nas empresas brasileiras. Revista Exame, Editora Abril, jul. 2018.

FLEURY, Maria T. L. Gerenciando a Diversidade Cultural: Experiências de Empresas Brasileiras. RAE - Revista de Administração de Empresas, v. 40, n. 3, p. 18-25, 2000.

GREENE, Anne-Marie; KIRTON, Gill. Views from Another Stakeholder: Trade Union Perspectives on the Rhetoric of 'Managing Diversity'. Industrial Relations Research Unit, Warwick, n. 74, p. 1-27, 2004.

GOFFMAN, Erving. Estigma: Notas Sobre a Manipulação da Identidade Deteriorada. 4. ed. Rio de Janeiro: Guanabara, 1988. 
GUIMARÃES, Antonio S. A. Democracia Racial. Cadernos Penesb, Niterói, n. 4, p. 33-60, 2002.

HIRATA, Helena.; KERGOAT, Danièle. A Divisão Sexual do Trabalho Revisitada. In MARUANI, Margaret; HIRATA, Helena (Orgs). As Novas Fronteiras da Desigualdade; Homens e Mulheres no Mercado de Trabalho. São Paulo: SENAC, 2003. p. $111-124$

INSTITUTO BRASILEIRO DE GEOGRAFIA E ESTATÍSTICA - IBGE. Censo demográfico 2010: Escolaridade e Rendimento Aumentam e Cai Mortalidade Infantil. 2012. Disponível em: $<$ https:// agenciadenoticias.ibge.gov.br/14209-asi-censo2010-escolaridade-e-rendimento-aumentam-e-caimortalidade-infantil.html $>$

INSTITUTO BRASILEIRO DE GEOGRAFIA E ESTATÍSTICA - IBGE. Pesquisa Nacional por Amostra de Domicílios - Síntese de Indicadores. 2014. Disponível em: <https://biblioteca.ibge.gov.br/ visualizacao/livros/liv94935.pdf>

INSPER. Mulheres \& Lucratividade. 2013 Disponível em: <https://www.insper.edu.br/noticias/ mulheres-lucratividade/ $>$

INSTITUTO ETHOS. Perfil Social, Racial e de Gênero das 500 Maiores Empresas do Brasil e Suas Ações Afirmativas. São Paulo, 2010. Disponível em: $<$ https://www.ethos.org.br/cedoc/perfil-social-raciale-de-genero-das-500-maiores-empresas-do-brasil-esuas-acoes-afirmativas-pesquisa-2010/>

JONES, James M. Racismo e Preconceito. São Paulo: Edgard Blucher, 1973.

KANTER, Rosabeth M. Contributions to Theory: Structural Determinants of Behavior in Organizations. In: KANTER, Rosabeth M. Men and Women of the Corporation. New York: Basic Books, 1993. p. 245-264.

KARTCHEVSKY-BULPORT, Andrée. O Sexo do Trabalho. Rio de Janeiro: Paz e Terra, 1986.

KERGOAT, Danièle. Em Defesa de uma Sociologia das Relações Sociais. Da Análise Crítica das Categorias Dominantes à Elaboração de uma Nova Conceituação. In: KARTCHEVSKY-BULPORT, Andrée, O Sexo do Trabalho. Rio de Janeiro: Paz e Terra, 1987.

KON, Anita. A Economia Política do Gênero: Determinantes da Divisão do Trabalho. Revista de Economia Política, v. 22, n. 3, p. 89-106, 2002.

LEITE, Marcia de P.; POSTHUMA, Anne C. Reestruturação Produtiva e Qualificação Reflexos
Sobre a Experiência Brasileira. São Paulo em Perspectiva, v. 10, n. 1, p. 63-76, 1996.

LOPES, Otavio B. A Questão da Discriminação no Trabalho. Revista Jurídica, v. 2, n. 17, 2000. Disponível em: $<$ https://revistajuridica.presidencia. gov.br/index.php/saj/article/viewFile/981/966>

MARTIN, Joanne. Hidden Gendered Assumptions in Mainstream Organizational Theory and Research. Journal of Management Inquiry, Stanford, v. 9, n. 2, p.207-216, 2000.

MENDES, Rodrigo. H. Diversidade Humana nas Organizações: entre a Teoria Acadêmica e a Prática Empresarial. 106 f. Dissertação (Mestrado em Administração de Empresas) - Fundação Getúlio Vargas, São Paulo, 2005.

MYERS, Aaron. O valor da diversidade racial nas empresas. Estudos afro-asiáticos, Rio de Janeiro, v. 23, n. 4, p. 483-515, 2003.

ORGANIZAÇÃO INTERNACIONAL DO TRABALHO - OIT BRASIL. Igualdade de Gênero e Raça, Erradicação da Pobreza e Geração de Emprego. 2013.

ORGANIZAÇÃO DAS NAÇÕES UNIDAS - ONU BRASIL. Guia de Orientação das Nações Unidas no Brasil para Denuncias de Discriminação Étnico-Racial. Brasília: Nações Unidas no Brasil. 2011. Disponível em: <https://www.unicef.org/ brazil/media/3721/file/Guia_de_orientacao_das_ Nacoes_Unidas_no_Brasil_para_denuncias_de_ discriminacao_etnico-racial.pdf $>$

ORGANIZAÇÃO DAS NAÇÕES UNIDAS - ONU BRASIL. Governo Brasileiro e ONU Firmam Acordo em Políticas de Gênero, Raça e Etnia esta Sexta (3). 2012. Disponível em: <https:// brasil.un.org/pt-br/60190-governo-brasileiro-e-onufirmam-acordo-em-politicas-de-genero-raca-eetnia-esta-sexta-3>

PIRES, Fernanda M.; LUCAS, Angela C.; ANDRADE, Sandra M.; AMORIM, Wilson A. C.; FISCHER, André L. Gênero e as Práticas de Gestão nas Melhores Empresas para se Trabalhar no Brasil. Gerais: Revista Interinstitucional de Psicologia, v. 3, n. 1, p, 81-94, 2010.

REITH, Stefanie L. Programas de diversidade de recursos humanos: uma análise sobre sua adoção no Brasil. Dissertação (Engenharia de Produção). São Carlos: UFSCar, 2014.

RIBEIRO, Maria. A. B. M. Raça - cor/etnia: reflexões sobre programas de diversidade do Brasil. In Diversidade: Avanço Conceitual para 
a Educação Profissional e o Trabalho. Brasília: Oficina Internacional Del Trabajo, 2002.

SANTOS, Carlos C. R.; JESUS de, Graciela G.; O Preconceito Racial dentro das Multinacionais como Impeditivo de Crescimento Profissional aos Negros no Brasil. In: SEGeT Simpósio de Excelência em Gestão e Tecnologia. Rio de Janeiro, 2010. p. 1-18.

SANTOS, Georgina. C. M.; COSTA, Bruna. V. L.; DUTRA, Shirley. E.; RODRIGUES, Ivete. Gestão da Diversidade: um Estudo entre as "Melhores Empresas para Você Trabalhar”. Seminários de Administração, 2008, São Paulo, FEA/USP. Disponível em: <http://sistema.semead.com. br/11semead/resultado/trabalhosPDF/445.pdf>

SARAIVA, Luiz A. S.; IRIGARAY, Hélio A. R. Políticas de Diversidade nas Organizações: Uma Questão de Discurso? RAE - Revista de Administração de Empresas. v. 49. n. 3, 2009. p. 337-348.

SECRETARIA DE POLÍTICAS PARA AS MULHERES - SPM. Programa Pró-equidade de Gênero e Raça - Rompendo fronteiras no Mundo do Trabalho. Brasília, SPM, 2016. Disponível em: $<$ http://www.onumulheres.org.br/wp-content/ uploads/2016/04/proequidade_para-site.pdf $>$

\footnotetext{
i Para designar as raças, cor ou etnia, usou-se a nomenclatura estabelecida pelo Instituto Brasileiro de Geografia e Estatística (IBGE). Para cor ou raça, considera-se negra a população preta ou parda.

ii Em outros âmbitos, surgiram as cotas, como a candidatura de mulheres a cargos eletivos, de 1995, e para o ingresso de alunos de escolas públicas de ensino médio, de baixa renda, negros, pardos e indígenas nas universidades públicas, que vem sendo implantada progressivamente desde 2004 (CARDOSO, 2013; BRASIL, 2014; SANTOS et al., 2008). iii Este programa conta com um comitê técnico- institucional e um comitê ad hoc, constituído por representantes de núcleos de estudos de gênero de dezenove universidades (BRASIL, 2011).

${ }^{\text {iv }} \mathrm{Na}$ Califórnia, o cargo de chefe de recursos humanos era ocupado por um homem negro.

$\checkmark$ Estas tabelas agrupam diferentes cargos em classes, às quais se atribuem faixas salariais, sendo usadas como referência para que as diferenças de remuneração entre cargos sejam consistentes (XERPAY, 2018?).
}

SHAUMAN, Kimberlee A.; NOONAN, Mary C. Legislating Equality: Statelevel Anti-Discrimination Laws and Labor Force Sex Stratification. In Annual Meetings of the Population Association of America. Detroit, MI, 2009.

SOARES, Sergei S. D. O Perfil da Discriminação no Mercado de Trabalho - Homens Negros, Mulheres Brancas e Mulheres Negras. 2000. Brasília: Diretoria de Estudos Sociais do IPEA. Disponível em: <http://repositorio.ipea.gov.br/ bitstream/11058/2295/1/TD_769.pdf $>$

STEIL, Andrea V. Organizações, Gênero e Posição Hierárquica -Compreendendo o Fenômeno do Teto de Vidro. Revista de Administração, São Paulo, v. 32, n. 3, p. 62-69, 1997.

VALOR ECONÔMICO. Prêmio reconhece as Melhores Empresas em Gestão de Pessoas, 2012.

XERPAY. Guia definitivo da Tabela Salarial: saiba como estruturar a sua, [2018?]. Disponível em: $<$ https://www.xerpa.com.br/blog/guia-definitivo-databela-salarial-saiba-como-estruturar-a-sua/>

ZANONI, Patrizia; JANSSENS, Mady; BENSCHOP, Yvonne; NKOMO, Stella. Unpacking Diversity, Grasping Inequality: Rethinking Difference Through Critical Perspectives. Organization, v. 17, n. 1, p. 9-29, 2010. 